\title{
Overseas Tourist Market Analysis and Overseas Promotion of Shanxi Province ${ }^{1}$
}

\author{
LI Lingling \\ Faculty of Ecotourism \\ Southwest Forestry University \\ Kunming, China \\ E-mail:506431143@qq.com
}

\author{
Mao Jian \\ Faculty of Ecotourism \\ Southwest Forestry University \\ Kunming, China \\ E-mail:356067137@qq.com
}

\author{
CHENG Xiping* \\ Faculty of Ecotourism \\ Southwest Forestry University \\ Kunming, China \\ E-mail:xipingcheng2012@163.com
}

\begin{abstract}
On the basis of tourism related data of Shanxi province, using pro-scene and other indicators index analysis of the overseas tourism market in Shanxi Province, the purpose is to reveal the spatial and temporal distribution and the overall characteristics of the overseas tourist market in Shanxi. Comprehensively grasp the situation of Shanxi overseas tourism market, systematically analyze the overseas tourists' output and its regional pattern. From a macro point of view of Shanxi inbound tourism market position in China; it can be further speeds up the overseas tourism development in Shanxi.
\end{abstract}

Keywords-Overseas travel; pro-scene index; Shanxi Province

Tourism has become one of the most important comprehensive industries and the leading role of tourism is more prominent economic development in the world. China has become the fourth largest inbound tourism reception country in the world, second only to France, the United States and Spain. At the same time China has the largest domestic tourism market in the world ${ }^{[1]}$.According to the National Tourism Administration statistics show that China's domestic tourism exceeded 4 billion passengers in 2015 , tourism income over 4 trillion yuan, and outbound tourism 120 million people. Domestic tourism, outbound tourism trips, domestic tourism consumption and foreign tourism consumption of China are listed in the world ${ }^{[2]}$. This paper aims to study the spatial and temporal structure of Shanxi overseas tourist market from the perspective of tourism flow, find out and summarize the rules and problems of overseas tourists market in Shanxi. To provide some help for the overseas tourism promotion of Shanxi.

\section{General Situation of the CASE}

Shanxi, which the west of the Taihang Mountains, referred to as "Jin"[3].It is located at latitude $34^{\circ} 34^{\prime} \mathrm{N} \sim 40^{\circ} 44^{\prime} \mathrm{N}$ and longitude $110^{\circ} 14^{\prime} \mathrm{E} \sim 114^{\circ} 33^{\prime} \mathrm{E}$. Direct employment of 515,000 people in Shanxi province by the end of 2015, indirect employees 210.8 million, of which rural tourism brand operators 10,000 households, direct employment of 50,000 people. In 2015, Shanxi received a total of 360 million domestic tourists trips, an increase of $20.22 \%$.Achieve total tourism revenue 344.75 billion yuan, an increase of $21.11 \%$. The number of inbound overnight tourists reached 593,800 , an increase of $5.14 \%$ over the same period of last year. Tourism foreign exchange income was 297 million dollars, up $5.83 \%$.Inbound tourism market in Shanxi is more stable, the ability to resist the international market risk tourism increased gradually and international tourism market is maturing.

\section{DATA SOURCES}

This research data mainly comes from the "Shanxi Statistical Yearbook" (2006 2015), "Chinese Tourism Statistics Yearbook" (2006 2015).

\section{ANAlysis OF OVERSEAs TOURIST MARKET StRUCTURE}

\section{A. Time structure analysis}

The time structure refers to the trend of the tourism market, which can be divided into seasonal knots and inter-annual changes. The seasonal and inter-annual variation of tourist market can be reflected by time intensity index. The calculation formula of time intensity index is expressed as:

$$
R=\sqrt{\sum_{i=1}^{12} \frac{(x i-8.33)^{2}}{12}}
$$

In the formula, $\mathrm{R}$ is the time intensity index of tourism demand, and $\mathrm{Xi}$ is the proportion of the total number of tourists in the whole year. $\mathrm{R}$ value not only depends on the change of

\footnotetext{
${ }^{1}$ Fund project: Science and Technology Innovation Fund of Southwest Forestry University(NO.C16040)

*Corresponding author: CHENG Xiping, Male, Ph. D., associate professor, School of ecotourism, Southwest Forestry University, research direction is forest ecology, E-mail: xipingcheng2012@163.com
} 
tourism demand, but also varies with the period of choice analysis; it is more suitable for comparison in different years. $\mathrm{R}$ value is closer to zero, the travel demand time distribution is more uniform. $\mathrm{R}$ value is bigger, the time change is bigger, and the difference of travel peak season is bigger.

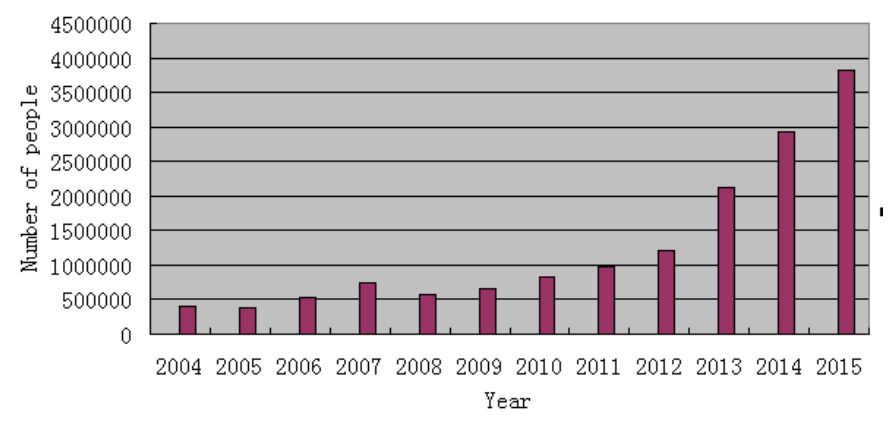

Fig. 1. Annual changes of overseas tourists in Shanxi

Formula (1) to calculate the inter-annual change intensity index of the overseas tourist market of Shanxi, and obtain the value of $\mathrm{R}$ is 5.64.From the $\mathrm{R}$ value can be seen, travel demand time of Shanxi overseas tourist market has great change.

The analysis of inter-annual variability from 2004 to 2015 can be divided into three stages from Fig 1.The first stage, the number of overseas tourists have a greater volatility from 2003 to 2006. The second stage, the number of inbound tourism into a peak in Shanxi Province, the average annual growth rate as high as $26.16 \%$ since 2006 to 2006 . International tourists increase more than twice. The third stage, inbound tourism growth rate slowed down compared to the second stage from 2012 to 2015, the average annual growth rate of $13.02 \%$ in 2015. Through the above analysis, the overall scale of overseas tourists is growing in Shanxi, but in the third stage is relatively small, the growth trend is generally.

\section{B. The spatial structure analysis}

Spatial structure is an important structure of tourist market. From the spatial distribution, divided into domestic source market and overseas tourists market, the spatial distribution of source markets is quantitatively analyzed by geographic concentration index ${ }^{[4]}$. The geographic concentration index formula expressed as:

$$
G=100 \sqrt{\sum_{i=1}^{n}\left(\frac{X_{i}}{T}\right)^{2}}
$$

In the formula, $\mathrm{G}$ is the source of the geographical concentration index, $\mathrm{X}$ said the number of tourists in the first I, $\mathrm{T}$ said the total number of foreign tourists, $\mathrm{n}$ for the number of tourists. $G$ value is closer to 100 , which indicates that the distribution of tourist market is concentrated and the source of tourists is fewer, so the development of tourism industry is not stable, and it is easy to be affected by the change of external factors. On the contrary, the closer the value of $\mathrm{G}$ is to 0 , the tourist markets are more dispersed and more diversified, and the tourism operation is more stable, the $G$ value is better for any tourist destination.
The relevant data of inbound tourism of major countries is brought into the formula (2), and the geographic concentration index of each year is calculated, as shown in table 1 .

TABLE I. GEOGRAPHIC CONCENTRATION INDEX OF MAJOR OVERSEAS TOURIST MARKET IN SHANXI

\begin{tabular}{|l|l|l|l|l|l|l|}
\hline Year & 2011 & 2012 & 2013 & 2014 & 2015 & Average \\
\hline G & 35.94 & 32.07 & 30.62 & 28.53 & 25.33 & 30.50 \\
\hline
\end{tabular}

It can be seen from Table I: The geographical concentration index presents a downward trend in Shanxi from 2011 to 2015, but the overall development of steady shows that the development of tourism in Shanxi stable gradually, foreign tourism market is gradually expanding in space. From the overall value and average value of the past five years, the $G$ value of geographical concentration index of Shanxi is relatively small. We can see that the value is relatively stable, indicating that the inbound tourism market structure diversified state $^{[5]}$. The main source countries constitute the basic stability, the market share continues to rise, it is conducive to the development of the inbound tourism market in Shanxi province.

\section{Spatial and temporal change analysis of preference scenery}

Preference scenery Li refers to the ratio of Mi that number of tourists in a certain country to Ml that number of inbound tourists to a place, with $\mathrm{Ci}$ what the country to travel to the country where the number of tourists to the country and $\mathrm{Cl}$ what the country the number of inbound tourists in tourism. So the formula is expressed as:

$$
L_{i}=\frac{M_{i} / M_{1}}{C_{i} / C_{1}}
$$

Among them, L is preference scenery of tourists in the country. Mi is number of inbound tourists in some region, $\mathrm{M}$ is region's tourism foreign population, $\mathrm{Ci}$ as the number of inbound tourists to travel to China, and $\mathrm{C}$ for the number of foreign visitors to China. But the size of the preference scenery and the number of visitors is not necessarily links. Depending on the value of $\mathrm{L}$, the degree of affinity can be further subdivided into four types: $0<\mathrm{L}<0.5$, indicating that the market for the strong non preference market. $0.5<\mathrm{L}<1$, that belongs to the weak non preference market. $1<\mathrm{L}<2$, indicating that the market is weak preference market. $L \geq 2$, indicating that the market preference for strong market. According to 2011-2015 the number of tourists and the number of travel to Shanxi, we were calculated 15 major tourist countries nearly 5 years preference scenery of Shanxi province, and the changing trend shown in Fig.2. 


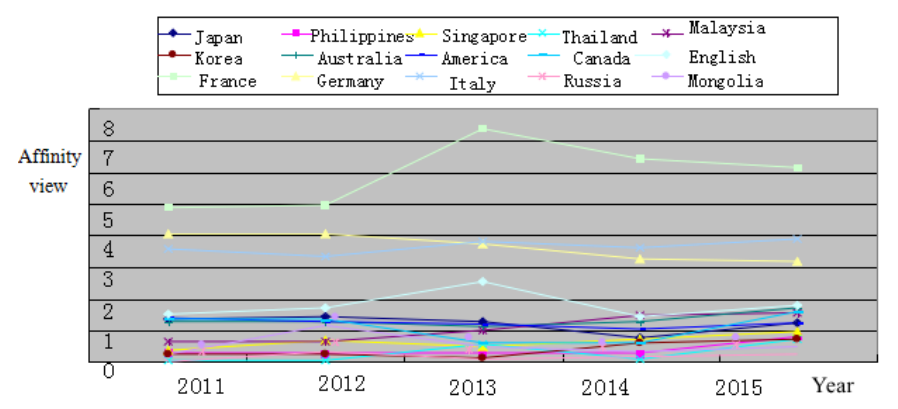

Fig. 2. The main overseas tourists market preference scenery trend of 2011-2015Shanxi Province

Since 2011, Shanxi overseas market is mainly France, Germany, Britain, Japan, the United States, Canada and other countries. Fig. 2 shows that France, Germany, Italy is a strong affinity market, which in 2011-2015. Annual preference scenery of France is greater than 4, reached a peak of 7.35 after a slight decline in 2013, and after more than 6 and has been stable in 2014. It can be clearly seen from Fig. 2 that in the case of the slow recovery of the European economy in 2011, the European market is generally good, which shows that the European market is less affected by its own economic impact. Japan, the United Kingdom, the United States, Canada and Australia markets preference scenery between 1 to 2 , belongs to the weak preference scenery. The British market preference scenery drops rapidly after peak of 2.53 in 2013.Japan has remained relatively stable trend, but below 1 in 2014.Because of the influence of the political relations between the two countries, and the comprehensive effect factors such as the yen. During the same period, the number of Japanese tourists visiting Korea decreased significantly, and the fluctuation of the other preference scenery market was not very large and relatively stable. South Korea, Malaysia, Thailand, Russia, Mongolia, Philippines and Singapore preference scenery basically are less than 1,which belongs to the sparse scenery tourist country, including the preference of Russia and Mongolia is always less than 0.5 , belongs to the preference for strong market.

\section{RESULTS AND DISCUSSION}

\section{Results}

Through the above analysis, this paper draws the following conclusions:

1) Overall, the scale of overseas tourists in Shanxi is growing.

2) The spatial pattern of overseas tourism market in Shanxi has not changed and diversified.

3) Shanxi overseas tourist market differentiation of the preference scenery is more obvious.

4) Europe, Asia Pacific and the Americas continue to maintain the status of the three major international tourist hot spots.

\section{E. Discussion}

1) From preference scenery, South Korea, Russia and Mongolia respectively belong to weak preference scenery market and weak hydrophobic scene, but South Korea, Russia and Mongolia is an important tourist in our country, so we should strengthen the promotion and the propaganda of the three countries, induce to travel of Shanxi in these countries to increase its share.

2) To strengthen overseas travel network promotion. Network has long been depth aspects of tourism, a positive and effective response to network competition has become a new challenge to promote outside Shanxi that determines the effectiveness of the promotion or even the success or failure ${ }^{[6]}$.

\section{REFERENCE}

[1] Bao Jigang. Tourism Geography(Revised Edition)[M].Beijing: Higher Education Press, 2012

[2] Yun Xia, Li Jie, Dong Likun, etc. Introduction to Tourism[M]. Beijing: Higher Education Press,2008

[3] Ma Yaofeng, Li Yongjun. Research on spatial region-division of inbound tourist flow in China[J].Human Geography,2001,16(6):44-46

[4] Zhao Dongxi. Study in the Influencing Factors of the Development of China's Provincial Inbound Tourism-Analysis Based on the Provincial Panel Data[J].Tourism Tribune,2008,23(1):41—45

[5] Huang Xiujuan. A Study on Choosing Fujian International Tourism Marketing Target[J]. Touriam Tribune, 2O05, 20(2):15-19

[6] Li xu, Qin Yaochen, Ni Xiaoju. Destination Choice Change and Its Influencing Factors of Inbound Tourists in China [J].Economic Geography, 2014 (6): 169-175. 